\title{
Implementasi Routing Protocol DSR pada Skenario Mobility Random Waypoint dengan menggunakan Propagasi Nakagami
}

\author{
Hasbi As Shiddi Qi, Radityo Anggoro, Muchammad Husni \\ Departemen Teknik Informatika, Fakultas Teknologi Informasi, Institut Teknologi Sepuluh Nopember \\ (ITS) \\ e-mail: onggo.informatika@gmail.com
}

\begin{abstract}
Abstrak-Mobile Ad hoc Network (MANET) merupakan jaringan wireless yang berasal dari kumpulan mobile node yang topologinya dapat berubah dengan cepat dan kapan saja. Aspek yang penting dalam MANET adalah protokol rute dimana protokol inilah yang mengatur sistem pencarian rute paket data dalam jaringan tersebut. Ada beberapa macam protokol rute pada MANET salah satunya adalah DSR. DSR merupakan pengembangan dari AODV. Perbedaan antara AODV dengan DSR adalah jumlah rute yang ditemukan dalam setiap proses pencarian rute. Dalam Studi ini, dilakukan penelitian terhadap kinerja DSR menggunakan Network Simulator 2 (NS-2). Uji coba dilakukan dengan membuat pola traffic connection dan pola pergerakan node yang kemudian disimulasikan dengan menggunakan script DSR.tcl. Proses tersebut akan menghasilkan file otuput berupa trace file. Trace file hasil dari simulasi akan dianalisis untuk menghitung Packet Delivery Ratio (PDR), Routing Overhead (RO), dan End-to-End Delay.
\end{abstract}

Kata kunci-MANET, AODV, DSR, NS-2.

\section{PENDAHULUAN}

$\mathrm{P}$ ERKEMBANGAN teknologi informasi dan komunikasi di era globalisasi saat ini berkembang dengan pesat, yaitu ditunjukkan dengan terciptanya berbagai macam teknologi yang membantu meningkatkan produktivitas manusia. Salah satu teknologi yang memudahkan manusia untuk saling berkomunikasi adalah Mobile Ad hoc Network (MANET). Pada MANET mobile host yang terhubung dengan wireless dapat bergerak bebas dan juga berperan sebagai router. Jaringan MANET adalah kumpulan dari beberapa wireless node yang dapat di set-up secara dinamis.

Dalam Studi ini, akan dilakukan studi kinerja terhadap protokol routing DSR pada topologi jaringan MANET berdasarkan Packet Delivery Ratio (PDR), Routing Overhead (RO), dan End-to-End Delay.

\section{TINJAUAN PUSTAKA}

\section{A. Mobile Ad Hoc Network (MANET)}

Mobile Ad hoc Network (MANET) memungkinkan terjadinya komunikasi jaringan tanpa bergantung pada ketersedian infrastruktur jaringan yang tetap. Setiap node dalam jaringan MANET dapat bertindak sebagai host dan router. Setiap node dapat saling melakukan komunikasi antara yang satu dengan yang lainnya tanpa adanya access point.

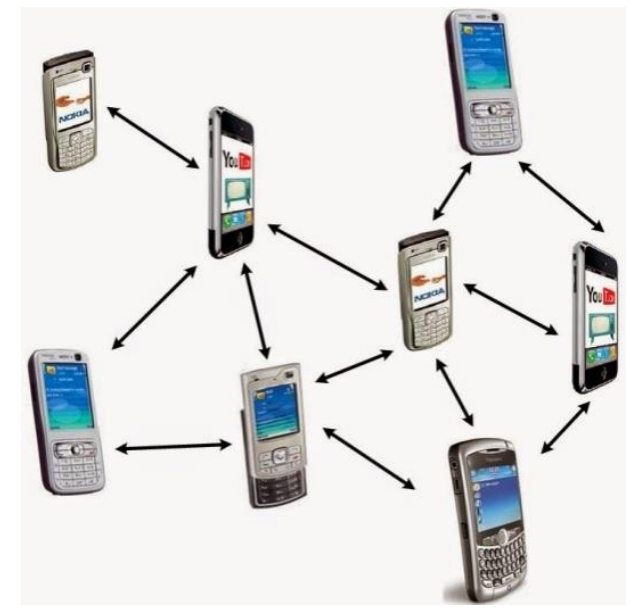

Gambar 1. Jaringan MANET [1]

Pada gambar 1 merupakan contoh penerapan jaringan MANET yang dibentuk dari sekumpulan perangkat mobile seperti ponsel. Perangkat mobile seperti ponsel harus mampu mendeteksi keberadaan perangkat lain dan melakukan pengaturan yang diperlukan untuk melakukan komunikasi dan berbagi data. Pada MANET memungkinkan perangkat untuk mempertahankan koneksi ke jaringan serta dengan mudah menambahkan dan menghapus perangkat pada jaringan. Karena pergerakan node yang dinamis, topologi jaringan dapat berubah dengan cepat dan tak terduga dari waktu ke waktu. Jaringan MANET bersifat desentralisasi, di mana organisasi jaringan dan pengiriman pesan harus dijalankan oleh node sendiri. [1]

Karakteristik dan kompleksitas dari MANET antara lain memiliki topologi dinamis, menggunakan multi-hop routing, jaringan topologi dinamis, energi dan bandwidth yang terbatas, keterbatasan keamanan dan melakukan pembangunan serta pengaturan jaringan secara mandiri [2].

\section{B. Dynamic Source Routing (DSR)}

Protokol Dynamic Source Routing (DSR) [3] memiliki banyak persamaan karakteristik dengan Protokol routing AODV. DSR memiliki konsep bebasis vektor dan menggunakan pendekatan multihop. DSR juga memiliki dua fitur utama yang mirip dengan AODV yaitu route discovery dan route maintenance. Perbedaan utama antara AODV dan DSR adalah jumlah rute yang ditemukan di setiap pencarian rute atau route discovery. 


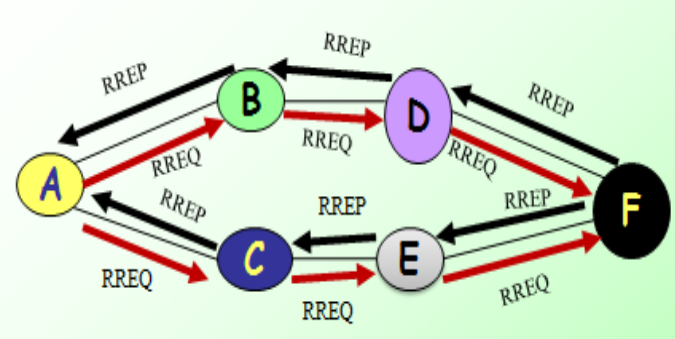

Gambar 2. Route discovery pada DSR

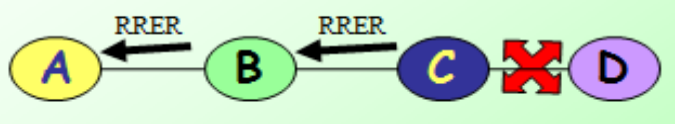

Gambar 3. Paket RRER pada DSR

Route discovery pada DSR terjadi ketika source node memerlukan rute untuk melakukan komunikasi dengan destination node, maka source node akan mengirimkan paket route request (RREQ) secara broadcast ke node-node tetangga di dalam jaringan dan menunggu route reply (RREP). Proses route discovery pada DSR ditunjukkan Pada Gambar 2.

Ketika node A (source node) hendak melakukan komunikasi terhadap node $\mathrm{F}$ (destination node), pertama kali node $\mathrm{A}$ mengirimkan paket RREQ secara broadcast ke node-node tetangganya yaitu ke node $\mathrm{B}$ dan node $\mathrm{C}$. Apabila node-node tersebut dalam hal ini node $\mathrm{B}$ dan node $\mathrm{C}$ bukan merupakan destination node, maka node tersebut akan meneruskan paket RREQ secara broadcast ke node tetangganya tetapi tidak ke source node. Selain itu, node B dan node C akan melakukan set up reverse path. Proses tersebut berulang hingga paket RREQ tersebut diterima oleh destination node yatiu node $\mathrm{F}$. Selanjutnya, node $\mathrm{F}$ akan mengiirmkan paket RREP sebagai balasan dari paket RREQ yang diterimanya. Node-node penerima paket RREP akan melakukan set-up forward path.

Route maintenance pada DSR adalah pengembangan sederhana yang ada pada route maintenance AODV. DSR juga menggunakan paket route error (RERR) untuk mengirimkan pesan error. Proses pengiriman paket RRER pada DSR ditunjukkan pada Gambar 3.

Pada saat terjadi kerusakan link yang menghubungkan antara node $\mathrm{C}$ dengan node $\mathrm{D}$, maka node $\mathrm{C}$ akan mengirimkan paket RRER ke node B. Selanjutnya, node B akan mengirimkan paket RRER ke node A. Setelah node A menerima paket RRER, proses komunikasi akan dilakukan kembali dengan menggunakan rute cadangan apabila masih tersedia. Apabila tidak tersedia rute cadangan, maka node A akan melakukan proses route discovery.

\section{VirtualBox}

VirtualBox adalah aplikasi multiplatform karena digunakan untuk meng-install sistem operasi di dalam sistem operasi utama pada sebuah perangkat komputer. Dengan menggunakan VirtualBox, sebuah perangkat komputer dapat menjalankan beberapa sistem operasi dalam waktu yang sama. Misalnya, pengguna dapat menjalankan Mac dan Linux di Windows, menjalankan Ubuntu di komputer dengan sistem operasi Windows, dan sebagainya.

VirtualBox didesain untuk para profesional dan pengembang di bidang Teknologi Informasi. VirtualBox dapat berjalan pada sistem operasi Windows, Mac OS X, Linux dan Oracle Solaris yang sangat ideal diaplikasikan untuk pengujian, pengembangan, dan simulasi berbagai sistem operasi pada satu mesin. [4]

Pada Studi ini, VirtualBox digunakan untuk menjalankan sistem operasi Linux yang berisi software NS-2 dan juga sebagai penghubung antara sistem operasi Windows dan Linux.

\section{Network Simulator 2 (NS-2)}

Network Simulator 2 atau biasa disebut NS-2 merupakan software simulasi jaringan dengan bahasa script yang sederhana, sangat memudahkan peneliti untuk melakukan konfigurasi jaringan dan mengamati hasil simulasi dari NS-2. NS-2 dikembangkan mengguanakan bahasa pemrograman C ++ dan Otcl. Berawal dari pengembangan simulator jaringan nyata oleh University of California Berkeley yang merupakan cikal bakal lahirnya Network Simulator. Pada tahun 1995 Defense Advanced Research Projects Agency (DARPA) membantu pengembangan Network Simulator melalui proyek Virtual Internetwork Terstbed (VINT). Sampai saat ini, para peneliti dan pengembang terus bekerja untuk menjadikan NS-2 lebih baik. [5]

Pada Studi ini digunakan NS-2 versi 2.35 untuk simulasi protokol routing DSR.

\section{E. Propagasi Nakagami}

Propagasi Nakagami awalnya diusulkan karena cocok dengan hasil empiris untuk propagasi ionosfer gelombang pendek. Dalam komunikasi nirkabel saat ini, peran utama propagasi Nakagami dapat diringkas sebagai berikut :

- Menggambarkan amplitudo sinyal yang diterima setelah dilakukan perhitungan rata-rata tracefile.

- Menyalurkan amplitudo sinyal secara terdistribusi.

- Mendistribusikan transmisi sesuai dengan data empiris yang lebih baik daripada model propagasi lainnya.

\section{F. $A W K$}

Awk adalah bahasa pemrograman yang digunakan untuk melakukan manipulasi data dan membuat laporan. Nama awk diambil dari nama akhir pembuatnya yaitu Alfred Aho, Peter Weinberger, dan Brian Kerningham. Pada beberapa sistem seperti linux, awk di-link-kan ke versi terbaru yang digunakan. Misalnya dalam distribusi Linux redhat, gawk merupakan link dari awk [6].

Awk dapat digunakan baik dalam command line maupun dimasukkan dalam sebuah skrip dengan melakukan scan baris per baris yang diperoleh dari standar input, file maupun output proses. Pada Studi ini AWk digunakan mendapatkan skrip dalam penghitungan Packet delivery ratio (PDR), End-to-end delay (E2D) dan Routing Overhead (RO) dari hasil trace pada Network Simulator 2. 


\section{DESAIN DAN PERANCANGAN}

\section{A. Deskripsi Umum}

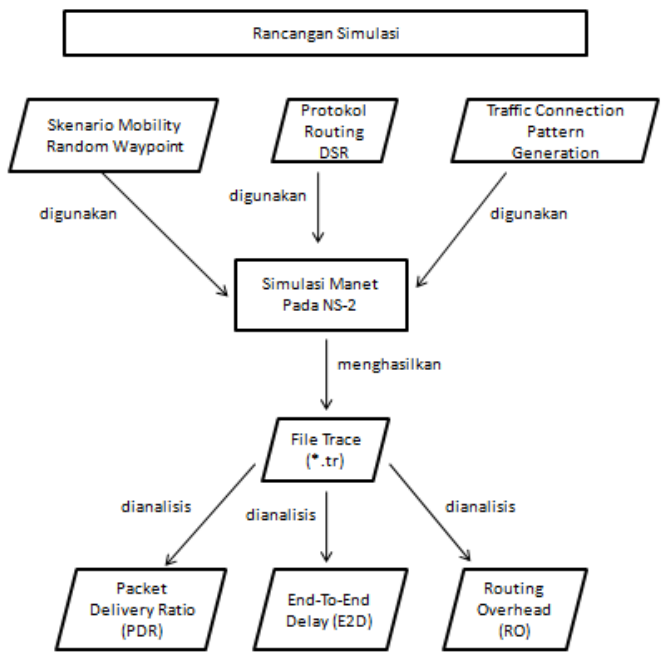

Gambar 4. Rancangan simulasi pada NS-2

Pada Studi ini akan dilakukan analisis tentang performa propagasi Nakagami pada MANET. Dalam pembuatan skenario MANET menggunakan mobility random waypoint dan telah ada pada NS-2 yaitu dengan cara men-generate file nodemovement (mobility generation) dan membuat koneksi antar node menggunakan traffic connection pattern. Rancangan simulasi yang dibuat dapat dilihat pada Gambar 4.

\section{B. Perancangan Metrik Analisis}

Metrik yang akan dianalisis pada Studi ini adalah Packet Delivery Ratio (PDR), Routing Overhead (RO), dan End-toEnd Delay (E2D) . Penjelasannya sebagai berikut:

\section{1) Packet Delivery Ratio (PDR)}

PDR dihitung dari perbandingan antara paket yang dikirim dengan paket yang diterima. PDR dihitung dengan menggunakan persamaan (1), dimana received adalah banyaknya paket data yang diterima dan sent adalah banyaknya paket data yang dikirimkan.

$$
P D R=\frac{\text { Ereceived }}{\sum \text { sent }} \times 100 \%
$$

\section{2) Routing Overhead (RO)}

Routing Overhead (RO) adalah jumlah paket kontrol routing yang ditransimisikan per data paket yang terkirim ke tujuan selama simulasi terjadi. RO dihitung berdasarkan paket routing yang ditransmisikan. Baris yang mengandung RO pada trace file ditandai dengan paket yang bertipe send (s) / forward (f) dan terdapat header paket dari protokol DSR.

\section{3) End-to-End Delay}

End-to-End Delay (E2D) dihitung dari rata-rata delay antara waktu paket diterima dan waktu paket dikirim. End-to-End Delay dihitung dengan menggunakan persamaan (2), dimana $\mathrm{t}_{\text {received[i] }}$ adalah waktu penerimaan paket dengan urutan / id ke$i, t_{\text {sent[i] }}$ adalah waktu pengiriman paket dengan urutan / id ke-i, dan sent adalah banyaknya paket data yang dikirimkan.

$$
E 2 D=\frac{\sum_{i \leq s e n t}^{i=0} t_{\text {received }[i]}-t_{\text {sent }[i]}}{\operatorname{sent}}(s)
$$

\section{IMPLEMENTASI}

\section{A. Implementasi Skenario File Node-Movement}

Perancangan skenario uji coba diawali dengan membuat pola traffic koneksi antara node secara acak menggunakan mobility random waypoint. Kemudian membuat koneksi dengan menggunakan traffic connection pattern. Pada Studi ini, pergerakan node-node menggunakan 4 variasi kecepatan maksimal yaitu $10 \mathrm{~m} / \mathrm{s}, 15 \mathrm{~m} / \mathrm{s}, 20 \mathrm{~m} / \mathrm{s}$ dan $25 \mathrm{~m} / \mathrm{s}$.

Skenario mobility random waypoint dibuat dengan mengenerate file node-movement yang telah ada pada NS-2 atau tools-nya biasa disebut 'setdest' yang nantinya akan menghasilkan output dalam bentuk .txt dan digunakan dalam file Tcl selama simulasi pada NS-2 sebagai bentuk pergerakan node yang berpindah-pindah.

\section{B. Implementasi Traffic-Connection Pattern Generation}

Traffic-connection dibuat dengan menjalankan file $\mathrm{Tcl}$ yang bernama cbrgen.tcl. Output dari program tersebut akan digunakan pada simulasi sebagai penghubung antara node. spesifikasi yang digunakan pada traffic-connection pattern ditunjukkan pada Tabel 1.

\section{Implementasi Network Skenario 2}

Pada implementasi ini dilakukan penggabungan antara hasil skenario grid dan skenario riil berupa file (mobility.tcl) dengan skrip TCL dari kode NS-2 yang diberikan parameter-parameter untuk selanjutnya dilakukan percobaan simulasi VANET pada NS-2. Parameter simulasi perancangan sistem VANET ditunjukkan pada Tabel 2.

Tabel 1.

\begin{tabular}{|c|c|c|}
\hline No. & Parameter & Spesifikasi \\
\hline 1 & Jenis traffic & CBR \\
\hline 2 & Jumlah paket per detik & 1 \\
\hline 3 & Jumlah seed & 1 \\
\hline 4 & Jumlah koneksi & 2 \\
\hline 5 & Agent & UDP \\
\hline \multicolumn{3}{|c|}{$\begin{array}{c}\text { Tabel } 2 . \\
\text { Parameter Simulasi }\end{array}$} \\
\hline No. & Parameter & Spesifikasi \\
\hline 1 & Network simulator & $\mathrm{NS}-2.34$ \\
\hline 2 & Routing Protocol & DSR \\
\hline 3 & Waktu Simulasi & 200 detik \\
\hline 4 & $\begin{array}{l}\text { Waktu Pengiriman Paket } \\
\text { Data }\end{array}$ & Nakagami $=0-200$ detik \\
\hline 5 & Area & $\begin{array}{l}500 \mathrm{~m} \times 500 \mathrm{~m} \\
900 \mathrm{~m} \times 900 \mathrm{~m}\end{array}$ \\
\hline 6 & Banyak node & $60,70,80,90$ \\
\hline 7 & Radius transmisi & $100 \mathrm{~m}$ \\
\hline 9 & Tipe data & Constant Bit Rate (CBR) \\
\hline 10 & Ukuran paket data & 512 bytes \\
\hline 11 & Protokol MAC & IEEE 802.11 \\
\hline 12 & Mode Transmisi & Nakagami \\
\hline 13 & Tipe Antenna & OmniAntenna \\
\hline 14 & Tipe Interface Queue & CMUPriQueue \\
\hline 15 & Tipe Peta & $\begin{array}{l}\text { MANET (random way } \\
\text { point) }\end{array}$ \\
\hline 16 & Tipe kanal & Wireless channel \\
\hline 17 & Tipe trace & Old Wireless Format Trace \\
\hline
\end{tabular}

Parameter Traffic-Connection Pattern 


\section{UJI COBA DAN ANALISIS HASIL}

Uji coba ini dilakukan dengan menggunakan sebuah komputer dan dalam lingkungan yang dibatasi. Berikut ini adalah spesifikasi perangkat dan lingkungan yang digunakan dalam simulasi ini.

- CPU Intel(R) Core(TM) i3 CPU @ 2.2GHz.

- Sistem Operasi Linux Ubuntu 14.04 64-bit.

- Memori 4 GB.

- Harddisk 640 GB.

- $\quad$ Network Simulator ns2.35

\section{A. Analisis Packet Delivery Ratio (PDR)}

Trace file hasil dari menjalankan program skenario nodemovement menggunakan model transmisi DSR dianalisis nilai PDR menggunakan script pdr.awk. Pada Tabel 3 dan Tabel 4 menunjukkan performa PDR pada skenario mobility random waypoint dengan menggunakan propagasi Nakagami menghasilkan nilai yang fluktuatif ketika kecepatan maksimal perpindahan node bertambah.

Tabel 3.

Packet Delivery Ratio (PDR) DSR Luas Lingkungan Jaringan $900 \mathrm{~m} \mathrm{x} 900 \mathrm{~m}$

\begin{tabular}{ccccc}
\hline \hline $\begin{array}{c}\text { Max } \\
\text { Speed } \\
(\mathrm{m} / \mathrm{s})\end{array}$ & Node 60 & Node 70 & Node 80 & Node 90 \\
\hline 10 & 80 & 78 & 82 & 87 \\
15 & 92 & 80 & 82 & 90 \\
20 & 91 & 92 & 84 & 87 \\
25 & 95 & 85 & 81 & 82 \\
\hline \hline
\end{tabular}

Tabel 4.

Packet Delivery Ratio (PDR) DSR Luas Lingkungan Jaringan $500 \mathrm{~m} \times 500 \mathrm{~m}$

\begin{tabular}{ccccc}
\hline \hline Max & \multicolumn{4}{c}{ PDR (\%) } \\
$\begin{array}{c}\text { Speed } \\
(\mathrm{m} / \mathrm{s})\end{array}$ & Node 60 & Node 70 & Node 80 & Node 90 \\
10 & 96 & 95 & 95 & 97 \\
15 & 98 & 94 & 98 & 98 \\
20 & 88 & 96 & 99 & 100 \\
25 & 95 & 93 & 94 & 92 \\
\hline \hline
\end{tabular}

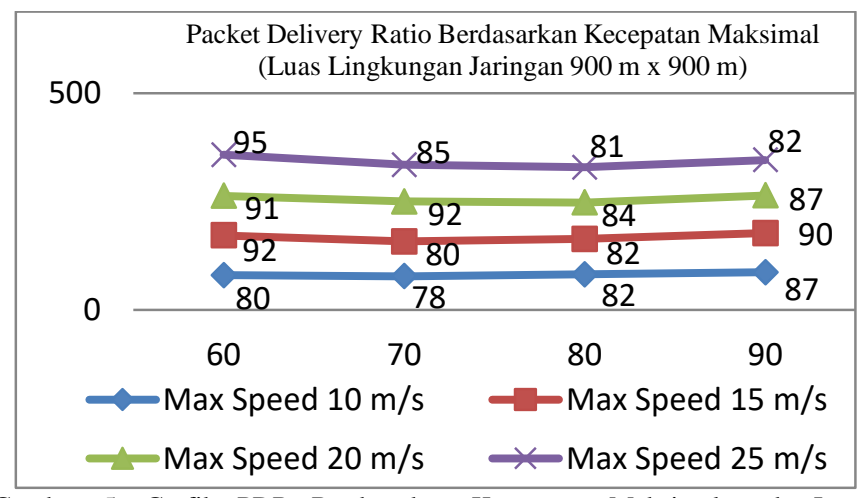

Gambar 5. Grafik PDR Berdasarkan Kecepatan Maksimal pada Luas Lingkungan Jaringan $900 \mathrm{~m}$ x $900 \mathrm{~m}$

Pada Gambar 5. menunjukkan grafik performa PDR dengan luas lingkungan jaringan $900 \mathrm{~m} \times 900 \mathrm{~m}$. Sebagai contoh, akan digunakan kecepatan maksimal perpindahan node sebesar 10 $\mathrm{m} / \mathrm{s}$ untuk memberikan bukti bahwa nilai PDR yang dihasilkan fluktuatif. Pada saat kecepatan maksimal perpindahan node 10 $\mathrm{m} / \mathrm{s}$ dengan jumlah node 60 , nilai PDR yang dihasilkan adalah $80 \%$. Pada saat jumlah node ditambah menjadi 70 , nilai PDR yang dihasilkan mengalami penurunan sebanyak $2,5 \%$ menjadi $78 \%$. Kemudian pada saat jumlah node ditambah menjadi 80 , nilai PDR yang dihasilkan mengalami peningkatan sebanyak $5,13 \%$ menjadi $82 \%$. Kemudian pada saat jumlah node ditambah menjadi 90, nilai PDR yang dihasilkan kembali mengalami peningkatan sebanyak 6,1\% menjadi $87 \%$.

Pada Gambar 6 menunjukkan grafik performa PDR dengan luas lingkungan jaringan $500 \mathrm{~m}$ x $500 \mathrm{~m}$. Sebagai contoh, akan digunakan jumlah node 70 untuk memberikan bukti bahwa nilai PDR yang dihasilkan fluktuatif. Pada saat jumlah node 70 dengan kecepatan maksimal perpindahan node $10 \mathrm{~m} / \mathrm{s}$, nilai PDR yang dihasilkan adalah 95\%. Pada saat jumlah kecepatan maksimal perpindahan node ditambah menjadi $15 \mathrm{~m} / \mathrm{s}$, nilai PDR yang dihasilkan mengalami penurunan sebanyak 1,05\% menjadi $94 \%$. Kemudian pada saat jumlah kecepatan maksimal perpindahan node ditambah menjadi $20 \mathrm{~m} / \mathrm{s}$, nilai PDR yang dihasilkan kembali mengalami peningkatan sebanyak 2,13\% menjadi 96\%. Namun pada saat kecepatan maksimal perpindahan node ditambah menjadi 25 , nilai PDR yang dihasilkan mengalami penurunan sebanyak $3,13 \%$ menjadi $93 \%$.

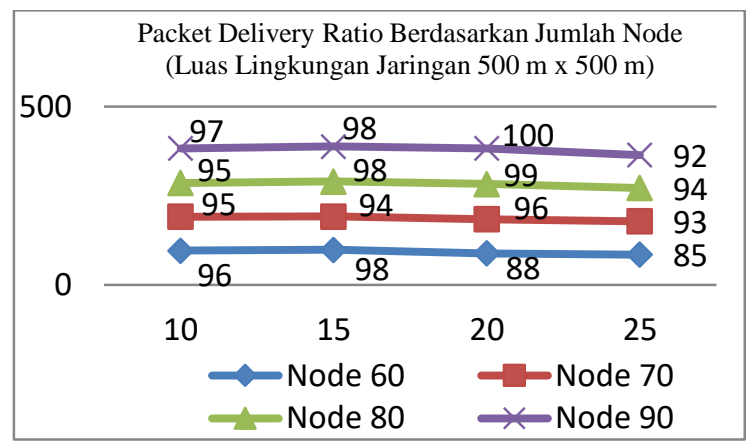

Gambar 6. Grafik PDR Berdasarkan Kecepatan Maksimal pada Luas Lingkungan Jaringan $500 \mathrm{~m}$ x $500 \mathrm{~m}$

B. Analisis Routing Overhead (RO)

Tabel 5.

Packet Delivery Ratio (RO) DSR Luas Lingkungan Jaringan $900 \mathrm{~m} \times 900 \mathrm{~m}$

\begin{tabular}{ccccc}
\hline \hline $\begin{array}{c}\text { Max } \\
\text { Speed } \\
(\mathrm{m} / \mathrm{s})\end{array}$ & Node 60 & Node 70 & Node 80 & Node 90 \\
\hline 10 & 1092,6 & 1898,6 & 1141,8 & 1924,6 \\
15 & 2131,2 & 1768,2 & 1185,4 & 1213 \\
20 & 1319,4 & 1315 & 1639,8 & 1429,2 \\
25 & 937 & 1444,6 & 1859,6 & 1880,8 \\
\hline \hline
\end{tabular}

Tabel 6.

Packet Delivery Ratio (RO) DSR Luas Lingkungan Jaringan $500 \mathrm{~m} \times 500 \mathrm{~m}$

\begin{tabular}{ccccc}
\hline \hline $\begin{array}{c}\text { Max } \\
\text { Speed } \\
(\mathrm{m} / \mathrm{s})\end{array}$ & Node 60 & Node 70 & Node 80 & Node 90 \\
\hline 10 & 628.8 & 350.2 & 561.8 & 537 \\
15 & 328.6 & 758.4 & 413.2 & 593.4 \\
20 & 648 & 465.2 & 887 & 486.6 \\
25 & 407.2 & 817.6 & 785.8 & 958 \\
\hline \hline
\end{tabular}


Trace file hasil dari menjalankan program skenario nodemovement menggunakan model transmisi DSR dianalisis nilai RO menggunakan script ro.awk. Pada Tabel 5 dan Tabel 6 menunjukkan performa RO pada skenario mobility random waypoint dengan menggunakan propagasi Nakagami menghasilkan nilai yang fluktuatif ketika kecepatan maksimal perpindahan node bertambah.

Pada Gambar 5 menunjukkan grafik performa RO dengan luas lingkungan jaringan $900 \mathrm{~m}$ x $900 \mathrm{~m}$. Sebagai contoh, akan digunakan kecepatan maksimal perpindahan node sebesar 20 $\mathrm{m} / \mathrm{s}$ untuk memberikan bukti bahwa nilai RO yang dihasilkan fluktuatif. Pada saat kecepatan maksimal node $20 \mathrm{~m} / \mathrm{s}$ dengan menggunakan jumlah node 60 , nilai $\mathrm{RO}$ yang dihasilkan sebanyak 1319,4 paket. Pada saat jumlah node ditambah menjadi 70, nilai RO yang dihasilkan mengalami penurunan sebanyak 0,33\% menjadi 1315 paket. Namun pada saat jumlah node ditambah menjadi 80 , nilai PDR yang dihasilkan mengalami peningkatan sebanyak $24,7 \%$ menjadi 1639,8 paket. Kemudian pada saat jumlah node ditambah menjadi 90 , nilai RO yang dihasilkan mengalami penurunan sebanyak $12,84 \%$ menjadi 1429,2 paket.

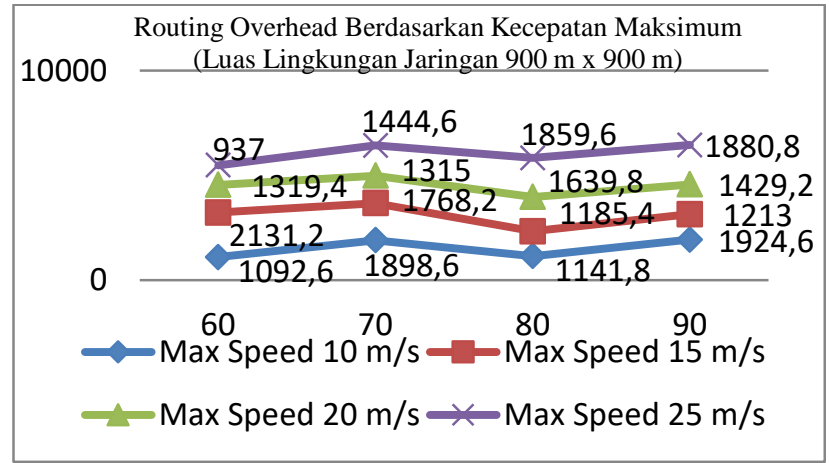

Gambar 7. Grafik RO Berdasarkan Kecepatan Maksimal pada Luas Lingkungan Jaringan 900 m x 900 m

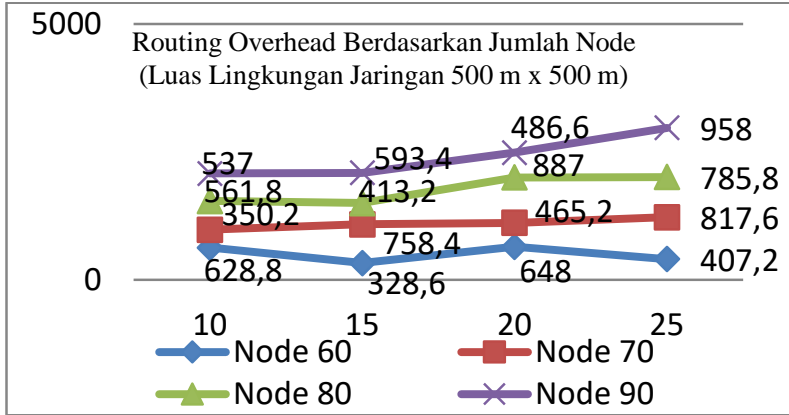

Gambar 8. Grafik RO Berdasarkan Jumlah Node pada Luas Lingkungan Jaringan $500 \mathrm{~m} \times 500 \mathrm{~m}$

Pada Gambar 7 menunjukkan grafik performa RO dengan luas lingkungan jaringan $500 \mathrm{~m} \times 500 \mathrm{~m}$. Sebagai contoh, akan digunakan jumlah node 60 untuk memberikan bukti bahwa nilai RO yang dihasilkan fluktuatif. Pada saat jumlah node 60 dengan kecepatan maksimal perpindahan node $10 \mathrm{~m} / \mathrm{s}$, nilai RO yang dihasilkan adalah 628,8 paket. Pada saat jumlah kecepatan maksimal perpindahan node ditambah menjadi $15 \mathrm{~m} / \mathrm{s}$, nilai RO yang dihasilkan mengalami penurunan sebanyak 47,74\% menjadi 328,6 paket. Namun pada saat jumlah kecepatan maksimal perpindahan node ditambah menjadi $20 \mathrm{~m} / \mathrm{s}$, nilai RO yang dihasilkan mengalami peningkatan sebanyak 97,2\% menjadi 648 paket. Kemudian pada saat kecepatan maksimal perpindahan node ditambah menjadi $25 \mathrm{~m} / \mathrm{s}$, nilai RO yang dihasilkan mengalami penurunan sebanyak $37,16 \%$ menjadi 407,2 paket.

\section{Analisis End-to-End Delay (E2D)}

Trace file hasil dari menjalankan program skenario nodemovement menggunakan model transmisi DSR dianalisis nilai E2D menggunakan script delay.awk. Pada Tabel 7 dan Tabel 8 menunjukkan performa End-to-End Delay pada skenario mobility random waypoint dengan menggunakan propagasi Nakagami menghasilkan nilai yang fluktuatif ketika kecepatan maksimal perpindahan node bertambah.

Tabel 7.

End-to-End Delay DSR Luas Lingkungan Jaringan $900 \mathrm{~m} \times 900 \mathrm{~m}$

\begin{tabular}{ccccc}
\hline \hline $\begin{array}{c}\text { Max } \\
\text { Speed } \\
(\mathrm{m} / \mathrm{s})\end{array}$ & $\begin{array}{c}\text { Node } \\
60\end{array}$ & \multicolumn{3}{c}{ E2D (second) } \\
\hline 10 & 0,08 & 0,2 & Node 80 & Node 90 \\
15 & 0,2 & 0,26 & 0,03 & 0,13 \\
20 & 0,03 & 0,05 & 0,16 & 0,06 \\
25 & 0,08 & 0,09 & 0,11 & 0,03 \\
\hline \hline
\end{tabular}

Tabel 8

End-to-End Delay DSR Luas Lingkungan Jaringan $500 \mathrm{~m} \times 500 \mathrm{~m}$

\begin{tabular}{ccccc}
\hline \hline $\begin{array}{c}\text { Max } \\
\text { Speed } \\
(\mathrm{m} / \mathrm{s})\end{array}$ & Node 60 & Node 70 & Node 80 & Node 90 \\
\hline 10 & 0.03 & 0.23 & 0.02 & 0.06 \\
15 & 0.01 & 0.18 & 0.01 & 0.03 \\
20 & 0.31 & 0.01 & 0.26 & 0.01 \\
25 & 0.18 & 0.57 & 0.16 & 0.19 \\
\hline \hline
\end{tabular}

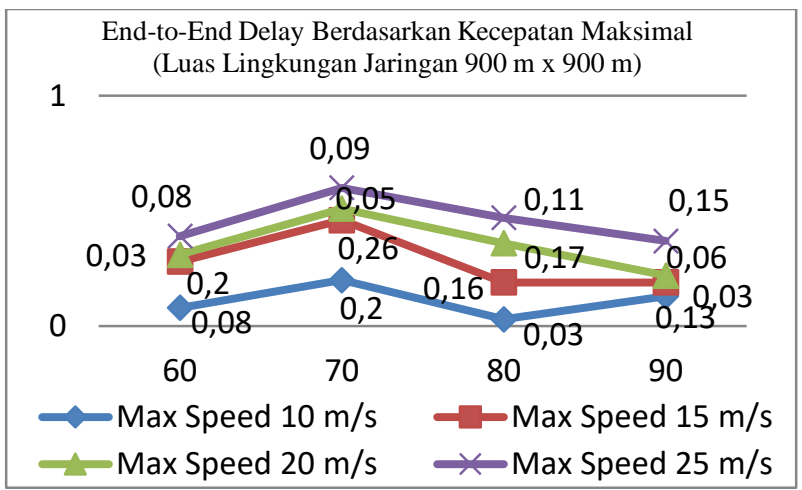

Gambar 9. Grafik E2D Berdasarkan Kecepatan Maksimal pada Luas Lingkungan Jaringan $900 \mathrm{~m}$ x $900 \mathrm{~m}$

Pada Gambar 8 menunjukkan grafik performa E2D dengan luas lingkungan jaringan $900 \mathrm{~m} \times 900 \mathrm{~m}$. Sebagai contoh, akan digunakan kecepatan maksimal perpindahan node sebesar 10 $\mathrm{m} / \mathrm{s}$ untuk memberikan bukti bahwa nilai E2D yang dihasilkan fluktuatif. Pada saat kecepatan maksimal perpindahan node 10 $\mathrm{m} / \mathrm{s}$ dengan jumlah node 60 , nilai E2D yang dihasilkan adalah 0,08 second. Pada saat jumlah node ditambah menjadi 70 , nilai E2D yang dihasilkan mengalami peningkatan sebanyak $150 \%$ menjadi 0,2 second. Namun pada saat jumlah node ditambah menjadi 80 , nilai RO yang dihasilkan mengalami penurunan sebanyak $85 \%$ menjadi 0,03 second. Kemudian pada saat jumlah node ditambah menjadi 90, nilai E2D yang dihasilkan 
mengalami peningkatan sebanyak $333,33 \%$ menjadi 0,13 second.

Pada Gambar 9 menunjukkan grafik performa E2D dengan luas lingkungan jaringan $900 \mathrm{~m}$ x $900 \mathrm{~m}$. Sebagai contoh, akan digunakan kecepatan maksimal perpindahan node sebesar 15 $\mathrm{m} / \mathrm{s}$ untuk memberikan bukti bahwa nilai E2D yang dihasilkan fluktuatif.Pada saat kecepatan maksimal node $15 \mathrm{~m} / \mathrm{s}$ dengan jumlah node 60, nilai E2D yang dihasilkan adalah 0,01 second. Pada saat jumlah node ditambah menjadi 70, nilai E2D yang dihasilkan mengalami peningkatan sebanyak $1800 \%$ menjadi 0,18 second. Namun pada saat jumlah node ditambah menjadi 80, nilai E2D yang dihasilkan mengalami penurunan sebanyak 94,44\% menjadi 0,01 second. Kemudian pada saat jumlah node ditambah menjadi 90, nilai E2D yang dihasilkan mengalami peningkatan sebanyak 200\% menjadi 0,03 second.

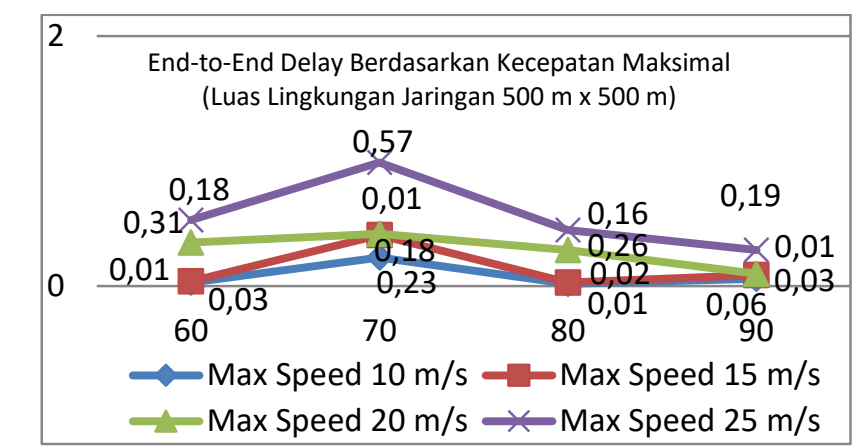

Gambar 10. Grafik E2D Berdasarkan Kecepatan Maksimal pada Luas Lingkungan Jaringan $500 \mathrm{~m}$ x $500 \mathrm{~m}$.

\section{KESIMPULAN DAN SARAN}

Dari hasil uji coba yang telah dilakukan, Hal - hal yang dapat mempengaruhi nilai PDR, E2D dan RO yang dihasilkan dari model propagasi Nakagami adalah:

- Jumlah node yang digunakan dalam simulasi.

- Kecepatan maksimal perpindahan node.

- Luas lingkungan jaringan.

Saran yang dapat diberikan dari hasil uji coba dan evaluasi dari Studi ini untuk pengembangan simulasi kedepan, antara lain:

1. Dapat dilakukan percobaan pada lingkungan VANET untuk penerapan model transmisi Nakagami.

2. Perlu dikembangkan penelitian menggunakan skenario yang lebih riil seperti menggunakan Simulation of Urban Mobility (SUMO) atau simulator lainnya.

\section{DAFTAR PUSTAKA}

[1] P. R. dan R. Dahiya, "Study and Analysis of Throughput, Delay and Packet Delivery Ratio in Manet Based DSR Routing Protocols," Int. J. Adv. Res. Eng. Technol., vol. 1, no. 2, 2013.

[2] S. dan Anil, "A Protocol for Reducing Routing Overhead in Mobile Ad Hoc Networks," J. Comput. Sci. Eng. Technol., 2014.

[3] M. K. M. dan S. R. Das, "Ad hoc on-demand multipath distance vector routing," Wirel. Commun. Mob. Comput., 2006.

[4] Oracle, "VirtualBox," 2017. [Online]. Available: https://www.virtualbox.org/manual/ch01.html.

[5] T. I. dan E. Hossain, "Introduction to Network Simulator NS2," Springer, 2012.

[6] "Bengkel Ubuntu," 2016. [Online]. Available: http://bengkelubuntu.org/teks/awk/Praktikum 01 - Berkenalan dengan AWK.pdf. 